\title{
A sense of optimism is important in times of challenge
}

Our first edition for 2021 coincides with glimmers of hope for a more stable and compassionate world to emerge from the pandemic shadow which still hangs over us all. Locally and globally, social workers continue to rise to the challenges of these difficult times. There is renewed energy to tackle the present-day legacies of the colonial past in Aotearoa and for social workers to contribute to fresh visions and practices which enhance social justice and inclusion. A sense of solidarity, shared purpose and mutual support is vital if we are to collectively support the development of social work into the future.

The eclectic collection of articles presented here reflects the desire to continue to design innovative and progressive responses across a wide range of service provision: to build meaningful partnerships and to listen with our eyes to the needs of individuals, whānau, and community. This capacity to reflect on past and current practice, to question our assumptions and be open to rethinking theory and practice in a time of profound social change is critical to our profession. A sense of optimism is very important. Times of challenge breed new ideas and solidarity with others. This journal can be a vehicle for some of the dialogue which is needed in the here and now.

We must also recognise that the social and economic challenges that impact on the daily lives of service users are real and pressing: the stress and uncertainty that comes with poverty, particularly the impact of housing unaffordability, continues to negatively impact the lives of too many people. Old (and new) prejudices continue to trouble Aotearoa. The world has not been won yet, but there are seeds of real change. The intent and energy of social workers is a key part of building, in alliance with others, a more equal future for our children and our communities.

In "He kaiwhakatere ahau: A (k)new practice model in the care of rangatahi and whānau" Georgina Denise Makoare (Ngāti Kahungunu), Zack Henare Makoare (Ngāti Kahungunu, Ngāti Porou, Rongomaiwahine, Ngāti Whatua), and Fiona Cram (Ngāti Pāhauwera) discuss an innovative practice model. A Kaiwhakatere position is funded through Te Taitimu Trust's Ngā Moko Ā Ngā Tūpuna initiative and is akin to a "professional auntie" who draws on her knowledge of whakapapa, whenua and whānau to engage rangatahi and whānau and build their connectedness and confidence as Māori. The authors describe and explore the Taikoko (rising spring tide) practice model of the Kaiwhakatere. "This model is grounded in Tākitimutanga to ensure that rangatahi and their whānau are connected to their cultural heritage, to their environment, and to a network of supports and relationships that facilitate their collective resiliency".

Hay, Pascoe, and McCafferty's article, "Social worker experiences in disaster management: Case studies from Aotearoa New Zealand" provides an overview of the final stage of an extensive project examining the role of social workers in disaster management. This final stage draws on interviews with 11 social workers and uses these to develop two case studies exemplifying the roles of social workers in disaster management. This pragmatic research approach provides an excellent resource for teaching practice and theories that are effective in disaster situations. The important lessons drawn from the case studies are particularly valuable, highlighting the benefits of communities pulling together and increasing social
AOTEAROA NEW ZEALAND SOCIAL WORK 33(1), 1-4. 
cohesion in the period of time immediately post-disaster. Recognising one's own entirely human responses of shock, fear or distress is important, and although this may result in some fluidity of boundaries, such expressions of emotion resonate with the humanist origins of social work, with its emphasis on congruence, empathy and genuineness. This reality also means social workers themselves may need support, debriefing and supervision, especially over time as exhaustion dealing with such exceptional circumstances sets in: "Working on the frontline, you just keep going. You push through the stress, exhaustion and anxiety to support others, but you do not necessarily give much thought to your own needs." In line again with humanistic approaches, the need for all professionals to be accepting of other people's reactions and to withold judgement was a key finding, in the face of significantly diverse responses to the disaster itself. Understanding responses to trauma and the ways trauma can be experienced, expressed and managed in idiosynchratic ways was also held as an important corrolary to non-judgemental practice. Finally, the role of social workers as advocates for services to offer continuing responses to longer term consequences of disasters was key to the role of good social work in post-distaster times.

In "Knocking on the door to integration": Korean immigrants' stories of seeking membership in Aotearoa New Zealand society, Hagyun Kim reports on a study that explored how nine South Koreans re-constructed life after immigration. Kim found that, in order to re-establish their lives, migrants gradually "knock ... on the door to integration" while retaining a sense of safety in their own ethnic community until they find that they are recognised as a full member of society. Kim argues that, if social work has a contribution to addressing ethnic minority groups' life-challenges, we must develop competencies in assisting Asian immigrants to understand their new surroundings and aiding their equal membership in society.
In "Re-writing the 'rules of engagement': Using critical reflection to examine ableist social work practice," Jessica Fox outlines her experience of using critical reflection as a research methodology to examine an incident in her practice. Fox employs deconstruction and reconstruction methods to analyse normative assumptions revealing how suppositions about impairment were underpinned by ableist discourses. Reflecting on this practice experience through a neurodiversity lens enabled Fox to generate new insights around the antioppressive potential for using a pluralistic approach that undermines hegemonic constructions of ability.

Liam Oades' article "Mamae Nui me te Takiwātanga: Surplus suffering and Autism Spectrum Disorder in school social work" reports on an investigation into the question of how social workers might deliver best practice to students living with Autism Spectrum Disorder. This carefully constructed article reports on a small research project with engaged practitioners. It builds on the notion of reducing or removing the surplus suffering which is often visited upon this group of service users in institutional settings and explores the scope for social workers to develop innovative therapeutic and community practice which can potentially improve the culture of school learning environments and social responses to student need.

In "Caught between a rock and a hard place: Social work in non-government organisations," Ashleigh Price explores contemporary social work practice in the NGO sector in Aotearoa. Drawing on the experiences of five experienced social workers engaged in practice in a range of NGOs, sobering themes emergedprimarily that social work practice in their organisations is underpinned by a sense of powerlessness. Consideration is given to several sub-themes including: freedom and powerlessness; the application of the principle of social justice at a macro level; professional dissonance; funding 
and resourcing constraints; and the notion of "othering." Price argues that the continuation of the neoliberal policy environment in Aotearoa poses a significant risk to the inclusion and achievement of social justice as a key feature and value of social work practice.

Inspired by her experience as a social worker in residential care homes for children in Aotearoa New Zealand, Andrea Greer conducted a study of these homes, seeking guidance for staff faced with behaviours she says are often described negatively as difficult or attention-seeking. Her analysis of interviews conducted with children who were residents of care homes, their parents and staff members led to some clear findings. For example, children and families wish to be fully informed of future plans, and staff should be focused on the development of trusting and therapeutic relationships with the children. Children highlighted the importance of the physical environment and its safety, including the negative impact of punitive rules and routines. All respondents acknowledged the benefit of, and right to have, ongoing connection with family and whānau.

Greer weaves these findings with concepts related to trauma, attachment theory, child-centred practice, neuroscience, and the stages of transition, and presents a framework intended to support the practice of those working with children and young people in residential care settings. Using the wharenui as a metaphor, she offers a useful guide to those working in the field. It acknowledges the impact of past trauma on children in care and a clear theoretical rationale for social work approaches that lead to healing and thriving, as opposed to the continued trauma often experienced in residential homes.

As always, our Commentary and Viewpoints sections bring fresh perspectives from practice, research and education. In these articles, the theme of this editorial is reflected-change and crisis can bring opportunities for change and innovation. First up, Justin Canty's commentary notes that at the height the Covid-19 lockdowns public health became a focus of daily conversation. The pandemic turned public health from being relatively unknown to many citizens to being a significant focus for education and public safety. While most social workers were generally unaware of public health, either as a discipline or specialization of medical practice, Canty draws our attention to several substantial points of connection with social work and explores the possibilities for social work and public health collaborations.

In "Animal abuse and family violence: Reflections from workshopping with veterinary," Michael Dale and Polly Yeung reflect on the contributions made by social work educators to teaching of first-year veterinary students. Workshops explored links between animal abuse and family violence. Dale and Yeung report that there is a growing body of research which documents a relationship between animal abuse, child abuse, and domestic violence.

Their article describes what was included in the workshops and explores future connections between human service and animal service professionals.

Anne MacAulay writes a personal reflection about 'Maintaining social work connections during lockdown' in her role as continuing professional development coordinator for the Aotearoa New Zealand Association of Social Workers. Anne reflects on how social workers used technology to stay connected during the 2020 1Covid-19 lockdowns and get support for continuing safe, ethical practice.

In "Expanding field education: Hope Trust Community Garden," Sandra Heerink, Vivienne Sinclair-Phillips, Alison Jagger, and Kathryn Hay reflect on the value of field education in a community garden setting from the perspectives of the field mentor, student and external field educator. 
The reflections highlight the value of this growing social service endeavour for learning and supporting social and environmental justice for clients and communities.

Our book reviews section this issue includes four reviews. Eileen Joy reviews Reassessing Attachment Theory in Child Welfare by Sue White, Matthew Gibson, David Wastell, and Patricia Walsh. Fritha Parkes reviews "Crossover" Children in the Youth Justice and Child Protection Systems by Susan Baidawi and Rosemary Sheehan. Carol Parkinson reviews New Theories for Social Work Practice:
Ethical Practice for Working with Individuals, Families and Communities edited by Robyn Munford and Kieran O'Donoghue. Finally, Matt Rankine reviews Supervision and Professional Development in Social Work Practice by Amanda Nickson, Margaret-Anne Carter, and Abraham Francis.

The editorial collective gratefully acknowledges the contributions of all our authors, and the support offered by our reviewers who continued to respond and offer constructive critique over 2020 and into 2021 despite the ongoing challenges posed by Covid-19. 